\title{
The water crisis and socio-ecological development profile of Rafsanjan Township, Iran
}

\author{
S. Mehryar, R. Sliuzas, A. Sharifi \& M. F. A. M. van Maarseveen \\ Department of Urban and Regional Planning and Geo-information \\ Management, Faculty of Geo-information Science and Earth \\ Observation (ITC), University of Twente, The Netherlands
}

\begin{abstract}
Water scarcity is a critical challenge in the Middle East. Historical analysis of case studies indicates that decades of water mismanagement and weak environmental planning play substantial roles in the water crisis. This paper illustrates the conflict between rapid development policies on the one hand and non-sustainable water resource management on the other in Rafsanjan Township, Iran over the period 1986-2014. Secondary literature and government reports are used to analyze the general environmental changes and responsive actions of government. A time series analysis of Landsat images illustrates the effect of economic development policies that have stimulated the expansion of pistachio orchards. Some possible responses based on a long-term socio-ecological resilient planning approach may provide some solutions, but will require a substantial rethinking of current policies and water management practices.

Keywords: water crisis, drought, water resource management, agro-economic development, socio-ecological system, spatial planning, change detection.
\end{abstract}

\section{Introduction}

Scientists warn about severe water scarcity and desertification in Middle East over future decades [1,2]. Generally, population growth and rapid economic development have been common in most Middle Eastern countries in recent decades. Confronting the high pressure of rapid developments, governments pursued more short-term benefits of overconsumption of water resources to overcome economic insecurity and increasing demand for food, water, space and 
jobs. However, the poor integration of development plans with natural resource management, and specifically water resource management, has caused long-term negative environmental impacts with an overall costs being much higher than the short-term benefits.

Iran, one of the Middle East's largest and most populous countries, is also one of the world's drought-prone areas. The average precipitation in Iran, of $252 \mathrm{~mm}$ per year, is less than one-third of the global average [3]. In addition to dry climate, Iran has experienced three decades of rapid population growth and urbanization $[3,4]$ and economic instability and sanctions [5] after the 1979 revolution and the eight years' war with Iraq.

The socio-economic pressure of these changes encouraged government to implement economic development plans, intended to satisfy growing demand in the country and to make the country more self-sufficient by supporting the industrial and agricultural sectors [6-8]. However, the thirst for rapid economic development has largely ignored the negative impact on natural resources by unplanned concentrations of population and land used throughout the potential agricultural and industrial areas. Currently, with the growing concern about the water crisis in Iran, the long-term negative impacts of former development plans and their incompatibility with water resources are being revealed. To illustrate the scale of the problem and the importance of a better integration between development policies and environmental resource management, this paper presents an environmental profile of the Rafsanjan Township.

Rafsanjan Township, with a population of more than 280,000 is an extreme example of a human settlement that is suffering from a sharp reduction of groundwater tables and increasing droughts. This township consists of five urban areas, four districts, 14 dehestan (above the village) and 305 villages occupying $8288 \mathrm{~km}^{2}$ or $4.5 \%$ of the Kerman Province. The city of Rafsanjan, located at $30^{\circ} 30 \mathrm{~N}$ latitude and $55^{\circ} 40 \mathrm{E}$ longitude, with a population of 151,000 (Census 2011), is the township's largest city. Rafsanjan Township and Kerman province are the main producers and exporters of pistachio in the world. Pistachio termed, the green gold of the country, is the main identity of this region. Almost $96 \%$ of agricultural lands in the township are allocated to the pistachio crop [9]. However, the growing concern with water scarcity is threatening the economic base of the region and its sustainability.

This profile presents a descriptive analysis of the changing demand and supply of water resources in Rafsanjan Township, reviews its current environmental problems, describes government responses to the challenge of water scarcity, and finally offers some suggestions contributing to the existing water crisis in the region. Several methods are used in the analysis which combines reviews of secondary literature and government reports supported by remote sensing (Landsat images of 28 years in time series of 1986, 1998, 2009 and 2014). The second and third sections of this paper describe the water demand and supply in Rafsanjan Township by analyzing changes of the main water demand drivers and comparing them with the historical water supply changes. The forth section discusses the institutional change of water resources management in the past. Next, section five describes the current environmental state of Rafsanjan. In section six, the recent 
responses of government to the combat water crisis in the region are analyzed. The final section concludes with some recommendations for improving water security in Rafsanjan through a strategy of integrating spatial planning with water resource management.

\section{Water demand}

Agriculture is the major economic activity in Rafsanjan Township, and the main user of water resources: $99 \%$ of water resources in the Rafsanjan region are provided by ground water, out of which $96.4 \%$ is consumed for agricultural purposes, $3.5 \%$ for domestic use and $0.1 \%$ for industry [9]. Increasing water demand in Rafsanjan Township is the outcome of two major drivers (and their subsequent pressures and impacts), namely agro-economic development and demographic change. These drivers are described below.

\subsection{Agro-economic development}

Agriculture has always been prioritized by the Iranian government as the main engine of national economic development [10]. After the Revolution (1978), agriculture-based development policies received even more attention. The new Islamic Republic government used the "Agricultural development" to satisfy the dramatically increasing food demand resulting from population growth and also to increase non-oil production revenues [11]. With the slogan of "Economic Jihad" (holy war), the government encouraged farmers to expand their planting area. Therefore, much pasture land was transformed into arable land without the need for government permission [11]. Subsidizing of water and energy for agricultural sector, big projects of building dams one after another, carrying out irrigation projects and importing higher technology of pumping wells were among the supportive actions of government to encourage their agricultural development policies $[5,10]$. Nevertheless, some experts believe that in spite of high investment on agriculture development, the sector's performance and contribution to GDP growth has been significantly less than expected $[5,10]$.

However, Rafsanjan and its main agricultural crop, pistachio, tell a somewhat different story. While agriculture in Iran is generally considered as an activity with a low income potential [5], in Rafsanjan people have profited greatly from the pistachio industry. The high value of pistachio attracted people and economic activity to the centers of pistachio production, so that the majority of Rafsanjan's inhabitants are currently active in the production, trade and distribution of pistachios: $33 \%$ of the township's population is active in agriculture (mainly production of Pistachio), 34\% in service jobs (including storage, distribution and trade of pistachio) and $25 \%$ in industry [12]. Pistachio export earnings account for around 10 percent of non-petroleum exports by value of Iran [13]. In 2006, 40\% of the world production of pistachio came from Iran and $43 \%$, of which came from Rafsanjan [14].

About $40 \%$ of Iran's pistachio lands are within the Rafsanjan Township; their area has grown dramatically over recent decades [15]. The agricultural 
development and vegetation change in the Rafsanjan Township can be seen in a time series study of NDVI data, which show the density and health of vegetation, derived from Landsat satellite images [16]. NDVI images are extensively used in determining health and extension levels of vegetation and assessing drought impact [17-20]. Higher values of NDVI indicate healthier vegetation while unhealthy or sparse vegetation shows a lower value. The NDVI images of Rafsanjan Township were prepared to explore the extension of agricultural lands in Rafsanjan between 1986 and 2014 (Figure 1). Result show that around 35,000 ha were added to the vegetated area (almost one third of its present planted area). Most agricultural expansion (52\%) occurred between 1998 and 2009 (Table $1)$, despite the drought that had started from 1999. Most of the agriculture expansion occurred around Rafsanjan City in the south and the cities of Noogh and Bahreman to the east (Figure 2). After 2009, there was no significant increase in vegetation observed in the region, perhaps indicating the impact of drought and poorer water accessibility.
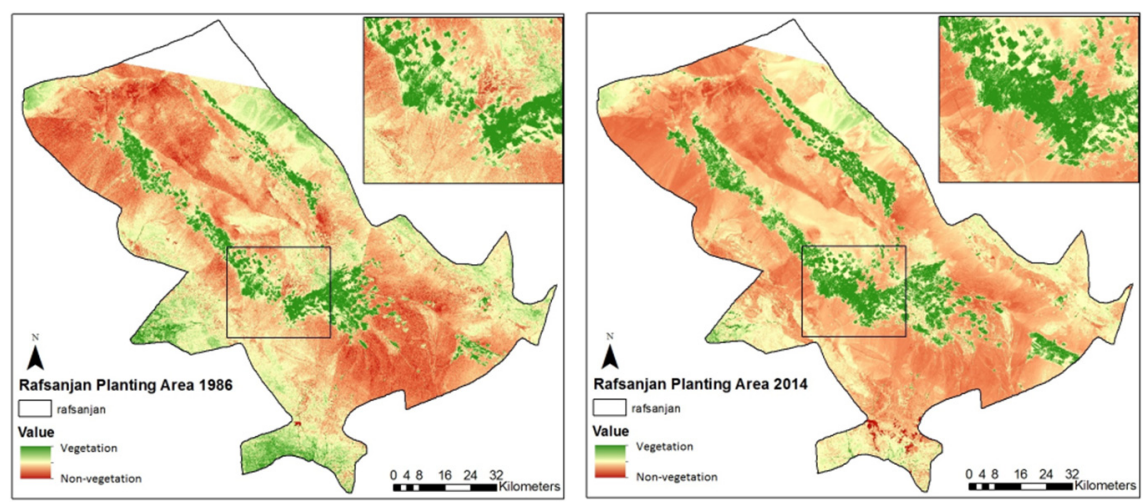

Figure 1: Expansion of agricultural land in Rafsanjan Township in 1986 and 2014.

Table 1: Agricultural land in Rafsanjan Township (1986-2014).

\begin{tabular}{|l|c|c|c|c|}
\hline & 1986 & 1998 & 2009 & 2014 \\
\hline $\begin{array}{l}\text { Agricultural } \\
\text { planted area (ha) }\end{array}$ & 73,000 & 86,000 & 104,000 & 110,000 \\
\hline
\end{tabular}

However the agriculture expansion planning in Rafsanjan did not consider the water resource capacity of this region. In spite of the relatively low water consumption of pistachio, still agriculture water consumption of the region exceeds its groundwater inflow. With the current agricultural area of 108,000 ha, the ground water withdrawal for agriculture is 663 million $\mathrm{m}^{3}$ or $96 \%$ of the entire groundwater withdrawal (by 685 million $\mathrm{m}^{3}$ ) [21] which is much larger than annual inflow of Rafsanjan's groundwater by 470 million $\mathrm{m}^{3}$. This means that even 

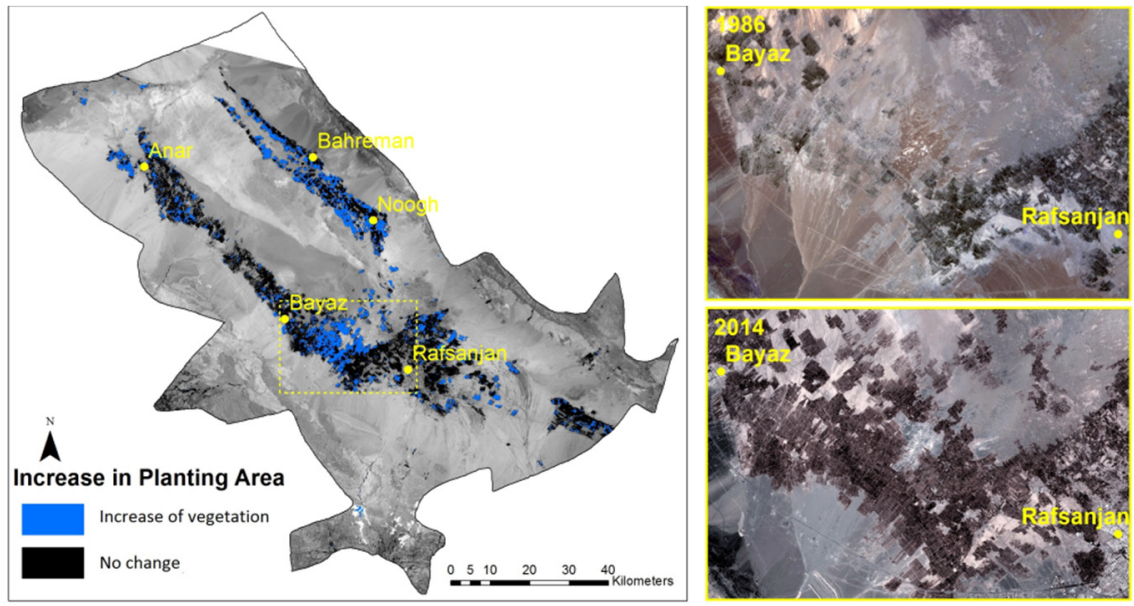

Figure 2: Vegetation increase in Rafsanjan Township between 1986 and 2014.

if all the agriculture land in Rafsanjan were to be used for pistachio, the current annual inflow from this aquifer would not still be able to provide enough water for Rafsanjan's agricultural areas.

\subsection{Population growth and change of lifestyle}

Population growth is often mentioned as a main driver of global water scarcity especially in countries undergoing rapid demographic change [22]. After the 1978 Islamic revolution, due to the government's policy of increasing the Islamic population and the lack of birth control, the country's population increased from 34 million to 63 million in 20 years [23]. This "baby boom" contributes to a dramatic increase in water demand and so a reduced supply of renewable fresh water per capita [5]. Increased food demands and employment stimulated the government to further develop the agricultural sector.

The population data from Statistical Centre of Iran [24] indicates that Rafsanjan Township, also experienced high population growth after the Islamic Revolution, with an annual growth rate of $2.5 \%$ between 1986 and 2006. However, the rural population decreased slightly after 1996 (Figure 3), following the rural-urban migration trend [9]. This led to increasing concentration of population in bigger cities, and the uneven distribution of population also puts pressure on the country's water resources. Currently, 61\% of Rafsanjan Township's population lives in urban areas and about 52\% lives in Rafsanjan city compared to just $17 \%$ in 1966. It is estimated that due to the growing urbanization trend of the country, the urban population of Rafsanjan will increase by $38 \%$ whereas its rural population will decrease by $-28 \%$ until 2024 [21].

Urban population growth is associated with the spatial urban expansion of Rafsanjan city. Urban land use change in Rafsanjan city and Rafsanjan Township 


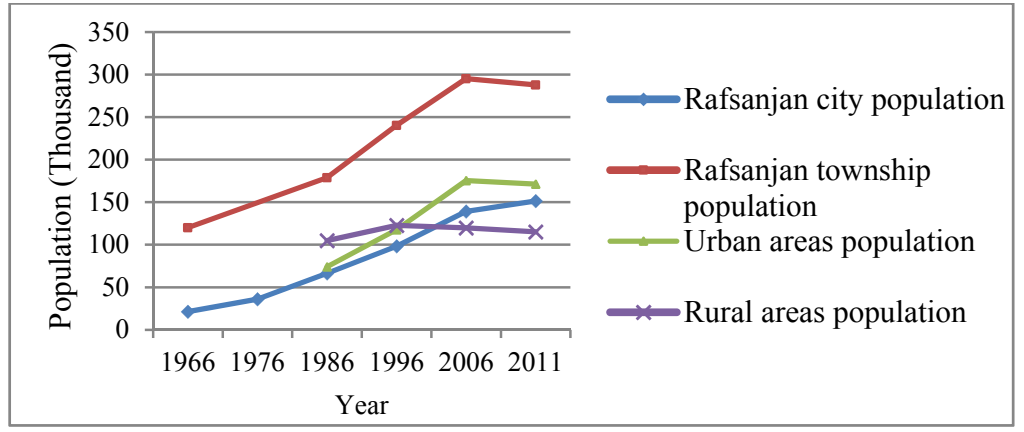

Figure 3: Population change in Rafsanjan city and Rafsanjan Township (SCI).

has also been studied using Landsat satellite images from 1986 to 2014 (Figure 4). The results indicate that the rate of urban expansion in Rafsanjan Township has exceeded the rate of population growth. The Rafsanjan Township urban area has grown from $42 \mathrm{~km}^{2}$ to $110 \mathrm{~km}^{2}$ in last 28 years (1986-2014) with an average expansion rate of $2.4 \mathrm{~km}^{2}$ per year. Like the population growth rate, the highest average urban expansion rate occurred between 1986 and 1998 by $114 \%$; much higher than population growth rate of $34 \%$ over the same period. The growing space use per capita perhaps reflects the modernization and changes of lifestyle in all aspects of Iranian life. Most of this expansion has taken place around the city of Rafsanjan, with a population growth rate of $48 \%$ and an urban expansion rate of $83 \%$ between 1986 and 1998 .

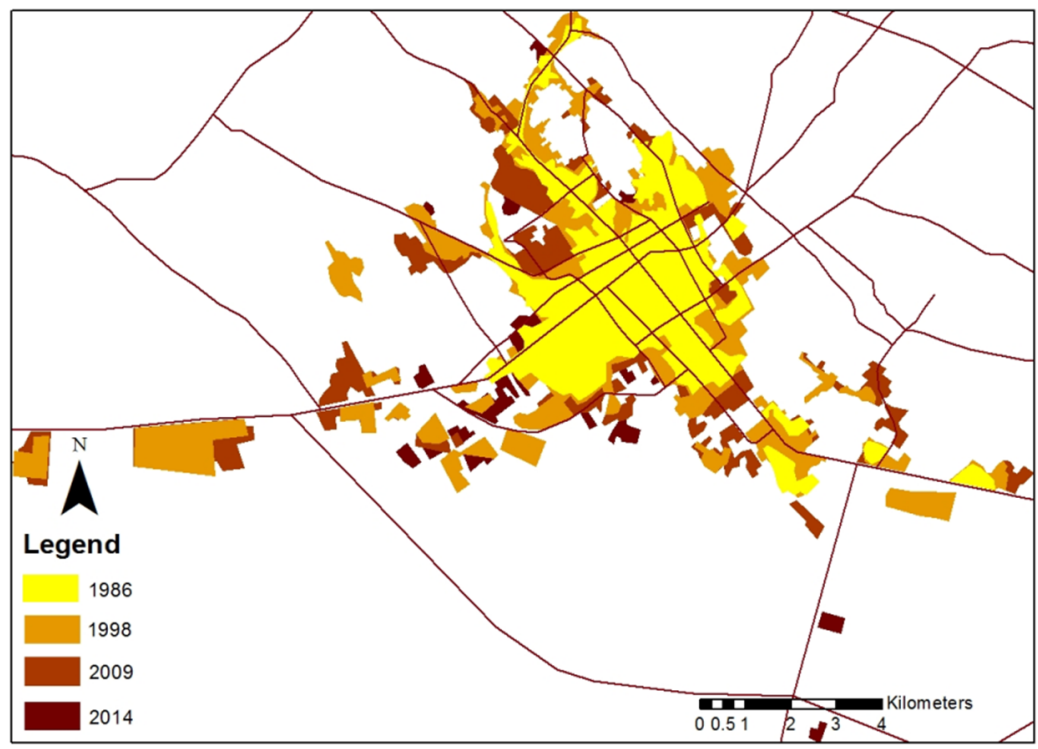

Figure 4: Rafsanjan City expansion from 1986 to 2014 (derived from Landsat images). 
Lifestyle changes and a growing consumer culture have also impacted domestic water use. Although the urban water use accounts for only $3.5 \%$ of water consumption of Rafsanjan region, still the growth of population and water consumption per capita have created problems for a sustainable urban water balance in this region. The average domestic water consumption of Rafsanjan basin in 1994 was 155 litres per day per capita, while by 2007 this increased to 175 litres per day per capita [21]. Currently the city of Rafsanjan available urban water is $14 \%$ less than the actual consumption, with a shortfall of -2.2 million $\mathrm{m}^{3}$ [21]. This is one of the highest urban water shortages in the province and it is expected to worsen.

\section{Water supply and the growing water imbalance}

The water supply situation in Rafsanjan has worsened due to the combined effects of meteorological and hydrological droughts. Rafsanjan plain is highly vulnerable to meteorological drought due to its arid and hyper-arid climate. Rafsanjan's average annual precipitation is $90 \mathrm{~mm}$, which is less than one third of the country average and one-ninth of the world average annual precipitation, while the potential average annual evaporation in the region is $3200 \mathrm{~mm}$ [9]. Rafsanjan plain has suffered a meteorological drought from 1999 due to a $63 \%$ decrease in precipitation [9].

This region is also suffering from severe hydrological drought due to the extreme groundwater drawdown in Rafsanjan Plain over recent decades. However, the symptoms of groundwater decline are not new. In 1974 Rafsanjan Plain was declared as "prohibited plain" due to a $20 \%$ over-exploitation of groundwater [21] with an annual well discharge of 334 million $\mathrm{m}^{3}$. Nevertheless, studying the statistics of groundwater discharge in Rafsanjan plain (Figure 5) show that water extraction reached 750 million $\mathrm{m}^{3}$ in 1989 , which was more than twice the amount of 1974. According to the most recent hydro-geological report [25], Rafsanjan's aquifer had $37 \%$ overexploitation of the groundwater balance and $22 \%$ overexploitation of its permissible level. The government has set the permissible annual extraction of 559 million $\mathrm{m}^{3}$ for this aquifer, while its actual annual extraction is recorded as 685 million $\mathrm{m}^{3}$ [9]. In 2009 the groundwater balance of Rafsanjan was -215 million $\mathrm{m}^{3}$ [21]. It is estimated that Rafsanjan has already used most of its groundwater resources and its aquifer has been classified as a "critical prohibited plain" by the government since 2006; implying that further well drilling in the region is not allowed and that groundwater withdrawal from licensed wells should be strictly controlled within specific limits set by the government

\section{The current environmental condition of Rafsanjan}

Meteorological drought and ground water depletion may only have a very slow and long-term impact on water accessibility, making the users and policy makers slow to act. However in Rafsanjan, the environmental symptoms of drought and water crisis are already apparent. Dramatic ground water depletion, loss of 


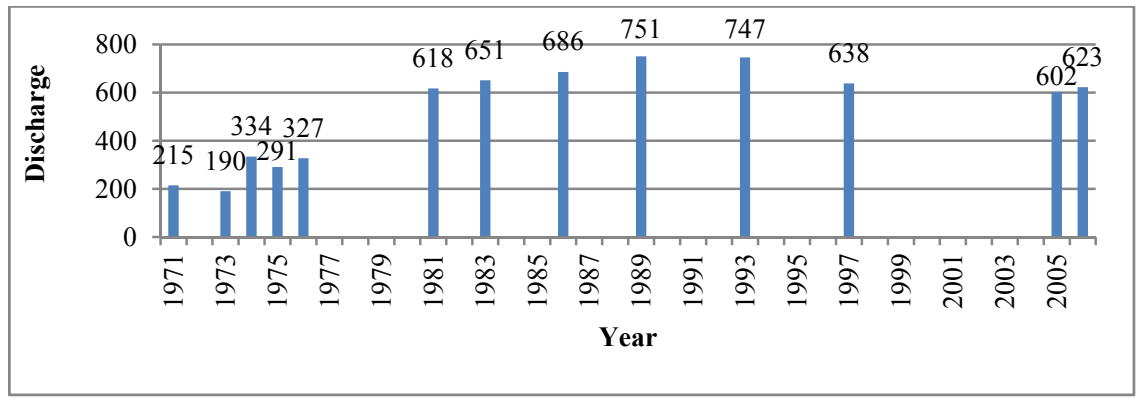

Figure 5: Total wells discharge in different sampling years. (Source: Iran Water Resource Management Company, 2012).

vegetation and production decreases are among the main environmental problems caused by current water crisis in Rafsanjan.

\subsection{Depletion of groundwater}

The rapid rise in the number of pumped wells has led to excessive groundwater withdrawal and consequently depletion of the groundwater level in Rafsanjan area. The hydrograph for the Rafsanjan plain (Figure 6) shows a dramatic drop in the groundwater level specifically after 1992. During a period of 30 years (19832013), the depth of Rafsanjan plain aquifer has fallen by $20 \mathrm{~m}$. The sharp drop of the groundwater table ( $1.5 \mathrm{~m}$ per year) demonstrates vividly the extent of over-use of non-renewable portion of groundwater.

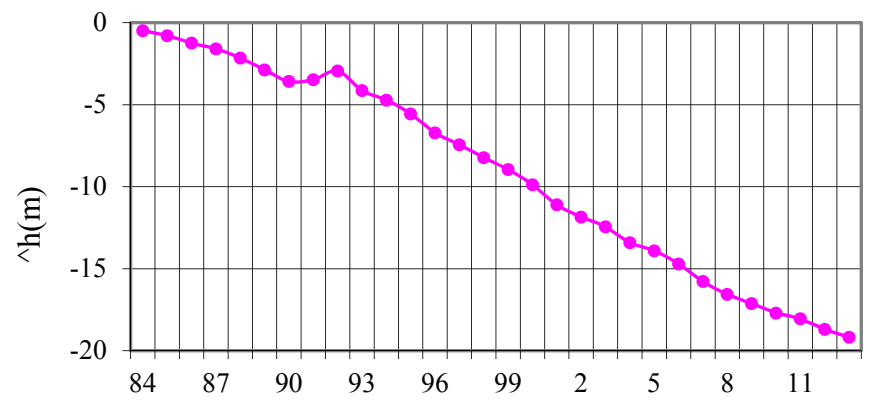

Figure 6: Ground water hydrograph of Rafsanjan Plain from 1983 to 2013. Source: wrs.arm.ir.

\subsection{Vegetation decrease}

The spatial impact of drought and water scarcity in Rafsanjan can be observed by evaluating the vegetation changes in time series. Here again, the NDVI time series data detect the changes of vegetation caused by drought. The vegetation transformation of the Rafsanjan Township shows major changes in the 28 years 
between 1986 and 2014 (Figure 7). Although there was widespread expansion of the planted area between 1986 and 2009, around $40 \%$ of these planted areas lost their vegetation after 1998. The level of vegetation in around $30 \%$ of Rafsanjan planted area has decreased to lower values. Reduction of vegetation value is because of either change of land use around the four cities (specifically around Rafsanjan city), or drought related decrease of green vegetation. From 2009 to 2014 , there has been only a decrease of vegetation value without any gain, unlike the previous period when both increases and decreases could be observed.

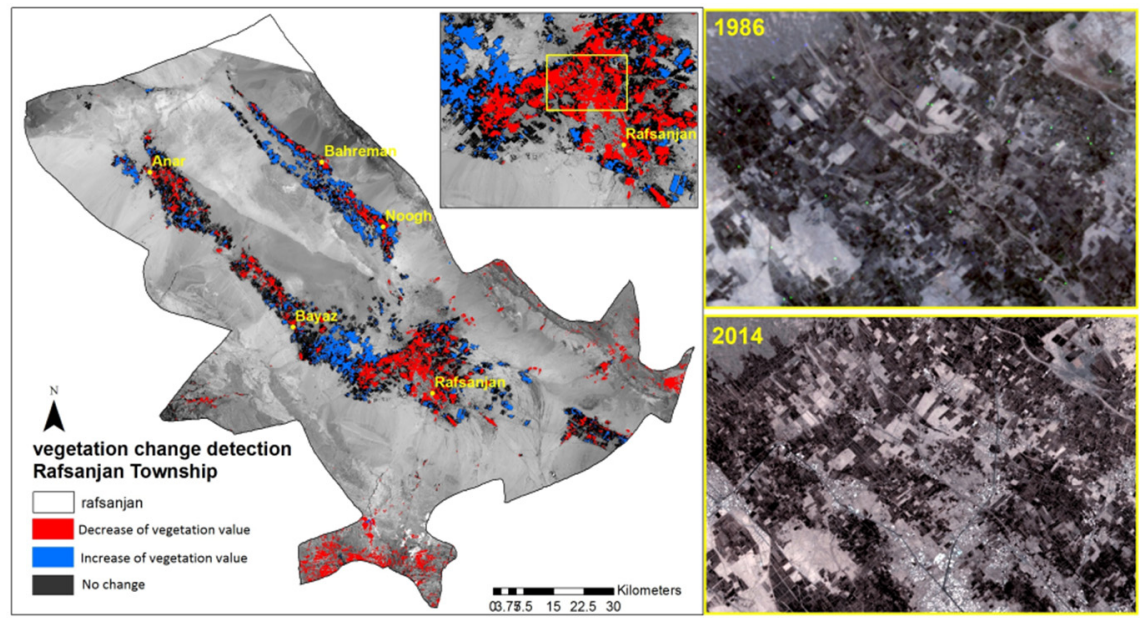

Figure 7: Vegetation change detection in Rafsanjan Township between 1986 and 2014.

Comparing the decreased vegetation of planted areas in Rafsanjan with the wells' discharge rates, well depth and groundwater level represents the current groundwater status in the region (Figure 8). The change detection map shows that, most of the negative change or loss of vegetation has occurred around the city of Rafsanjan. However, the wells discharge data of 2004-2005 illustrates the same area around Rafsanjan city with a lower discharge rate due to the low groundwater level. The cities of Rafsanjan in the south of the aquifer and Noogh and Bahreman in the east have the lowest groundwater levels. In some parts, even the wells $300 \mathrm{~m}$ deep cannot access water. Most of the dry wells, with zero or very low discharge rate, are also concentrated around the Rafsanjan city area.

The vegetation decrease has led to a reduction in pistachio production in the region as well. While the production and export of pistachio has long been a matter of national pride in Iran, for the first time ever Iran is being overtaken as the top pistachio exporter by the United States. Despite the large expansion of pistachio orchards, its agricultural production is declining over time. 

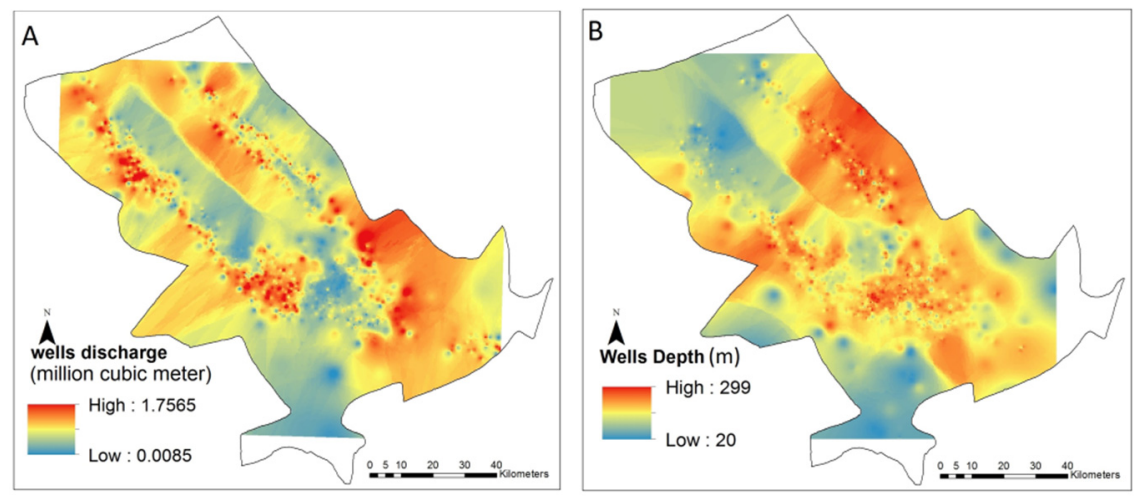

Figure 8: (a) Well discharge rate. (b) Wells Depth in Rafsanjan Township.

\section{Governmental and institutional responses}

\subsection{The evolution of the water supply system techniques and institutions}

In Rafsanjan, like many other arid cities of Middle East, groundwater has been withdrawn through both traditional and advanced pumped well systems. Traditionally, water was extracted from alluvial fans formed by seasonal streams at the interface of the mountains and the plains, through a system of tunnels and wells known as "Qanat". The Qanat system consists of a main gently sloping tunnel (about 1:1000) and vertical shafts that convey water from deep aquifers in highlands to the surface at lower levels by gravity [26, 27]. Water withdrawal in the Qanat system has some ecological benefits [28-30]; (a) it minimizes water loss from evaporation because water transportation and storage is underground; (b) it exploits groundwater only when it is available in the aquifer through natural replenishment, without overexploitation of renewable resources. Generating more than ecological benefits, Qanats were also used to manage water in an effective collective system. They used to be constructed by local experts and wealthy individuals but their maintenance and constant repair required teamwork that led to the diffusion of ownership. Some Qanats used to have even up to 200-300 owners at the same time [30]. The collective ownership of Qanats could successfully link the local communities in managing their own water resources in common [29]. Moreover, Qanats also had equitable water distribution systems as well. Every land owner took a share of water according to where his land was located (distance from spring and quality of the land) and the water was used only based on each farmers share. As a result, farmers used to cultivate the areas only to the extent that they could irrigate them with their share of water [31]. Considering these benefits, the traditional technology of Qanat has been a most effective and sustainable system over time in spite of the water scarcity challenges of the area.

However, the Qanat is no longer economically feasible. Pumped wells were introduced in Iran in the 1960s [32] as one of the socio-ecological outcomes of 
Iranian land reform in White Revolution of 1963 [22, 29]. Consequently, most Qanats have dried up due to the overuse of pumped wells and depletion of groundwater. The technological transformation from Qanats to pumped wells, has generated socio-ecological and institutional changes that have transformed access to groundwater [33], in what has been called the "silent revolution" [34].

After the land reform of 1962, all the lands were transferred from feudal landlords to peasants, in the process turning a large number of peasants into landlords and decreasing the size of the land holdings. The new land holdings were too small and fragmented to maintain the Qanat system [29]. Therefore, the new landlords, who access to water, invested in wells instead of repairing Qanats, because wells are more flexible and productive [34]. The pumped wells, unlike the Qanats, were neither owned nor managed collectively. In the new system individuals or small groups of farmers own and manage their wells and, as both energy and water are heavily subsidized by the government, water is generally a very cheap commodity for farmers to use [5]. Therefore, the pumped well system implied a shift from ground water as a "common resource" public good, to a private good. Consequently, the system of water resource management has transformed from communal management towards private ownership and management and the role of the state as "manager" of natural resources has been under significant pressure.

This transformation is also evident in Rafsanjan. In just four decades, from 1963 to 2006 the number of deep wells on the Rafsanjan plain had increased from 77 (PBO, 1995) to 1392 and the annual well discharge of groundwater increased about three times (from 215 to 623 million $\mathrm{m}^{3}$ ). The 148 currently functional Qanats of this region are now only responsible for $0.1 \%$ of the whole groundwater discharge (Jamab [9]).

\subsection{Actions to combat water crisis in Kerman region}

In 2013, the Iranian government pledged an annual 2 billion US\$ fund, to address the country's water crisis [35] and called for serious water conservation efforts, including actions at provincial level. In 2014, three main institutions of Kerman Province, the Kerman Regional Water Management Company, Kerman Agriculture Jihad, and Kerman Water and Sewage Water Company, in collaboration with other major stakeholders approved 16 regulations to address the water crisis. These regulations focus on three aspects: supply, demand and management. In supply, the only suggested regulation is about transferring water from the north and the south. A total of $27,000 \mathrm{~km}$ pipeline project is expected to be completed within 10 years to transfer water from the source to the orchards. However, the past experiences in Iran have shown that water transfer projects often worsen the situation and may cause further water crises [36]. Such projects address the symptoms and in doing so may attract more population and development to the areas that could otherwise not support them. In terms of demand, almost all of the suggestions concentrate on agriculture. Seven regulations are related to exploiting the benefit of modern technology and techniques of irrigation, efficient planting, educating farmers and also decreasing the agriculture lands based on the water availability of the regions. The management related regulations mostly focus 
on controlling the water use from the government's side. Six regulations concern identifying and blocking the illegal wells, creating accurate monthly reports of the water use and overcoming the technical problems of water meters and pumping systems, even though past attempts to do just this have largely failed.

Although more efficient irrigation systems, controlling the mechanisms of groundwater withdrawal and projects to transfer water seem effective solutions for short term, they are all temporary solutions. The government has always tried to use modern engineering techniques and control systems to decrease water overexploitation in recent decades but these efforts have not been effective in decreasing groundwater depletion. It seems that the water crisis in Rafsanjan needs long-term cooperation between planning and water management, coupled with an integrated socio-ecological view that is still missing from current government actions and policies. Lesson has to be learnt from the management of Qanat system which has been mainly a collective management carried out by all stakeholders.

\section{Discussion and conclusion}

The above historical analysis of water-related challenges in Iran, reveals that there has been a rapid but perhaps ill-conceived development in the country which was accelerated by the White revolution, the Islamic revolution and the post-war situation. Iran's development plans have mostly focused on economic development, self-sufficiency and self-reliance regardless of the environments boundary conditions and the potential long-term environmental costs. The negative impacts of these developments on the groundwater resources of Rafsanjan are symptomatic of this approach. Although water scarcity is now threatening the whole country, the specific crisis in Rafsanjan gains attention because of the high value agricultural production in this region.

Most of the solution strategies and actions from the government are again focused on maintaining the production and economic benefits from pistachios while treating the symptoms rather than the long-term causes of the problem. Efficient irrigation and modern agriculture systems, controlling overexploitation by government and water transfer projects are only good for short-term solutions. However, it has been argued in this paper that even if all agriculture lands in Rafsanjan changes to the low water consumption pistachio orchards using highefficiency irrigation systems, still the required water for pistachio land cannot be provided by the current aquifer inflow. Overexploitation of Rafsanjan's aquifer is a structural problem that threatens to undermine agricultural productivity and economic prosperity. In this situation it seems unlikely that engineering solutions or controlling systems alone will be effective.

This is the time for water scarce cities of Iran to adopt a long-term and interlinked socio-ecological perspective. The water crisis, as an integrated land and water management challenge, must be considered in a process of sustainable spatial planning. Spatial planning is a tool of government that assists in balanced distribution of population and land uses on different scales and in balance with natural and human resources. In sustainable spatial planning the relationships between land management and water management will have explicit attention. 
Currently, Rafsanjan and other similar cities in Iran require more long-term strategies that deepen socio-ecological system integration. In a sustainable and resilient socio-ecological system, the direct linkages and relations between social systems (planning, management, human rules and regulations) and ecological system (natural resources) are of paramount importance. The water crisis in Rafsanjan is a good example of the failure of planning to consider such linkages. Water, land use and population have not been managed in an integrated and coordinated way in Rafsanjan. An adaptive socio-ecological system management is required which can not only cope with the current water scarcity of the region but also adapt to possible future changes and emerging situations. It is possible that the current crisis marks a transition to a new social, ecological and economic situation based on the water resource capacities of this region. In this situation, the future development of the region must be managed through a more resilient socioecological system view that considers coping, adapting and transforming to new situations in water crisis areas. The case of Rafsanjan indicates that natural resource management is not yet sufficiently considered in the spatial planning of this region's development.

\section{References}

[1] H. Tropp and A. Jagerskog, "Water scarcity challenges in the Middle East and North Africa (MENA)", Human Development Paper. UNDP. http:/hdr.undp.org/hdr2006/pdfs/background-docs/Thematic_Papers/ SIWI.pdf, 2006.

[2] D. Michel, A. Pandya, S. I. Hasnain, R. Sticklor, and S. Panuganti, "Water Challenges and Cooperative Response in the Middle East and North Africa", Brookings Institution, Washington, DC. (Available at http://www.brookings.edu/research/papers/2012/11/water-security-middleeast-iwf.), 2012.

[3] A. Alizadeh and A. Keshavarz, "Status of agricultural water use in Iran", in Water Conservation, Reuse, and Recycling: Proceedings of an IranianAmerican Workshop, 2005, pp. 94-105.

[4] Z. Fanni, "Cities and urbanization in Iran after the Islamic revolution", Cities, vol. 23, pp. 407-411, 2006.

[5] K. Madani, "Water management in Iran: what is causing the looming crisis?" Journal of Environmental Studies and Sciences, pp. 1-14, 2014.

[6] O. Gilanpour, "Challenges of Iran's agriculture sector in accession Process to the WTO", in Proceedings of Eighth European Trade Study Meeting, Vienna. Retrieved on http://www.etsg.org/ETSG2006/papers/ Gilanpour.pdf, 2006.

[7] A. R. Khorami and S. Pierof, “The Role of Agriculture in Iran's Economic Development", 2013.

[8] H. C. Metz, Iran, a country study: B\&R Samizdat Express, 2013.

[9] Jamab, "Upgrading Study of Water Comprehensive Plan", Madar Consultant, Water Research Department, Tehran, Iran, 2011. 
[10] A. Shakoori, "Planning and Agricultural Development in Iran", Critique: Critical Middle Eastern Studies, vol. 15, pp. 265-282, 2006.

[11] I. Kalantari, "The environmental failure in protecting lagoons", M. Jamshidi, ed.: Tehran, Iran: Etemad newspaper, 2015, p. 14.

[12] Iran National Census, ed.: Statistical Center of Iran, 2011.

[13] R. Sedaghat, "Constraints in Production and Marketing of Iran's Pistachio and the Policies Concerned: An Application of the Garret Ranking Technique", International Journal of Nuts and Related Sciences (IJNRS), vol. 2, 2011.

[14] S. Razavi, "Pistachio production, Iran vs. the world," in IV International Symposium on Pistachios and Almonds 726, 2005, pp. 689-694.

[15] T. J. Jaghdani and B. Brümmer, "Demand for Irrigation Water for Pistachio Production from Depleting Groundwater Resources in Rafsanjan County", 2010.

[16] C. J. Tucker, "Red and photographic infrared linear combinations for monitoring vegetation", Remote sensing of Environment, vol. 8, pp. 127150, 1979.

[17] A. J. Peters, E. A. Walter-Shea, L. Ji, A. Vina, M. Hayes, and M. D. Svoboda, "Drought monitoring with NDVI-based standardized vegetation index", Photogrammetric engineering and remote sensing, vol. 68, pp. 71$75,2002$.

[18] J. Al-doski, S. B. Mansor, and H. Z. M. Shafri, "NDVI Differencing and Post-classification to Detect Vegetation Changes in Halabja City, Iraq", 013.

[19] G. Gopinath, G. Ambili, S. J. Gregory, and C. Anusha, "Drought risk mapping of south-western state in the Indian peninsula - A web based application", Journal of Environmental Management, 2015.

[20] S. Himanshu, G. Singh, and N. Kharola, "Monitoring of Drought using Satellite Data", 2015.

[21] RDPI, "Integrated Water Resources Management and Planning in Kerman Basin", Rahbord Danesh Pooya Institute, Kerman Regional Water Authority 2009.

[22] K. Madani, "Reasons behind Failure of Qanats in the 20th Century", presented at the World Environmental and Water Resources Congress 2008, Honolulu, Hawaii, 2008.

[23] F. Roudi-Fahimi, Iran's family planning program: responding to a nation's needs: Population Reference Bureau Washington, DC, 2002.

[24] SCI. Statistical Centre of Iran, (Online).

[25] MPO, "Comprehensive study of climate adaptability", IWRM Company, ed.: Tehran, Iran: Management and Planning Organization, 2003.

[26] P. W. English, "Qanats and lifeworlds in Iranian plateau villages", Yale F\&ES Bulletin, vol. 103, pp. 187-205, 1998.

[27] F. Boustani, "Sustainable water utilization in arid region of Iran by Qanats", in Proceeding of World Academy of Science, Engineering and Technology, 2008, pp. 213-216. 
[28] Z. Adeel, B. Schuster, and H. Bigas, "What Makes Traditional Technologies Tick? A Review of Traditional Approaches for Water Management in Drylands", ed.: Hamilton (ON), United Nations University, 2008.

[29] M. R. Balali, Towards reflexive land and water management in Iran: linking technology, governance and culture: Wageningen Universiteit (Wageningen University), 2009.

[30] H. Ahmadi, A. N. Samani, and A. Malekian, "The Qanat: A living history in Iran", in Water and Sustainability in Arid Regions, ed.: Springer, 2010, pp. 125-138.

[31] GIAHS, "Qanat Irrigated Agricultural Heritage Systems", M O Jihad-eAgriculture, ed.: GIAHS, 2014.

[32] E. Ehlers, A. Saidi, P. Beaumont, M. Bonine, and K. McLachlan, "Qanats and pumped wells: the case of Assad'abad, Hamadan", Qanat, kariz and khattara: traditional water systems in the Middle East and North Africa., pp. 88-112, 1989.

[33] R. C. Foltz, "Iran's water crisis: cultural, political, and ethical dimensions", Journal of Agricultural and Environmental Ethics, vol. 15, pp. 357-380, 2002.

[34] F. Molle, T. Shah, and R. Barker, "The groundswell of pumps: Multilevel impacts of a silent revolution", in ICID-Asia meeting, 2003.

[35] N. Soroush. (October 16, 2014). Political Dimensions of Iran's Water Crisis.

[36] A. Gohari, S. Eslamian, A. Mirchi, J. Abedi-Koupaei, A. M. Bavani, and K. Madani, "Water transfer as a solution to water shortage: a fix that can backfire", Journal of Hydrology, vol. 491, pp. 23-39, 2013. 